\title{
Public-service Advertisement And Core Socialist Values Education
}

$$
\text { Chen Pengyu }{ }^{1, a,}{ }^{*} \text {, Liu Kaiyuan }{ }^{2, b} \text { and Chen Xinwen }{ }^{3, c}
$$

1,2,3School of Journalism \& Communication, Jiangxi Normal University, Nanchang, Jangxi, China

acpy19980101@163.com, b594627603@qq.com, c274844335@qq.com

*Chen Pengyu

Keywords: Public-service Advertisement, Core Socialist Values, Public Communication

\begin{abstract}
The core values of socialism are clearly defined from the national level, social level and individual level. In order to make the socialist core values deeply rooted in the hearts of the people, it is necessary to take various effective ways to integrate them into the people's life, and public service advertising is one of the effective ways. The combination of public service advertising and socialist core values makes socialist values better spread.
\end{abstract}

\section{论公益广告与社会主义核心价值观教育 \\ 陈鹏羽 $1, a$, 刘开源 $2, b$, 陈新文 $3, c$ \\ $1,2,3$ 江西师范大学新闻与传播学院, 南昌, 江西, 中国 \\ acpy19980101@163.com, b594627603@qq.com, c274844335@qq.com \\ ”陈鹏羽}

关键词: 公益广告; 社会主义核心价值观；大众传播

中文摘要. 社会主义核心价值观是从国家层面、社会层面和个人层面明确界定的。为了使社 会主义核心价值观深入人心, 就要采取各种有效的方式来使其融入人民的生活之中, 而公益 广告就是其中一个有效的方式。将公益广告与社会主义核心价值观结合起来, 使得社会主义 价值观得以更好地传播。

\section{1. 社会主义核心价值观的作用}

从思想层面上讲,社会主义核心价值观是以马克思主义的指导思想为基础的,在坚持毛泽 东思想、邓小平理论、三个代表重要思想和习近平中国特色社会主义新思想基础上提出的, 是对党的指导思想的继承和发展。社会主义核心价值观的提出, 将原本抽象的理论变得具 体，更容易被人们接受。

从个人和社会层面看,社会主义核心价值观是从个人和社会层面来解读的，有利于人们 在爱国、敬业、诚信、友爱等方面的发展, 从而促进人们全面发展。对社会来说, 有利于促 进社会朝着更加自由、平等、公正、法治的方向发展, 建立健全新时期的法律法规, 做到有 法可依、有法必依、执法必严、违法必究, 使人们有话可说, 有困难找党, 从而引领社会进 步。

从国家层面看,社会主义核心价值观使全国人民努力建设富强、民主、文明、和谐的国 家, 有利于凝聚全国的力量, 为了在 2050 年全面全面实现小康社会, 实现中华民族的中国 梦而奋斗。 


\section{2. 广告在社会主义核心价值观的传播上的作用}

“推动社会主义核心价值观的大众化是培育和践行社会主义核心价值观的重要体现, 两 者在本质上是一致的。所谓大众化, 对于核心价值观而言, 就是使之成为 '大众化的', 用 来“化大众的', 最后成为 '大众的”。”[1]而公益广告是促进社会主义核心价值观普及的重要途 径。

社会主义核心价值观大众化进程中的公益广告是一种在全社会以传播核心价值观为主题 的手段和模式, 是公益广告的一种具体形态, 是党和政府主导作用与社会组织和公民个人主 体作用相结合的向公众展示和阐释社会主义核心价值观的内容和理念, 从而促进公众接受先 进的政治理念和价值观念的信息传播手段和與论导向模式。 ${ }^{[2]}$ 将社会主义核心价值观与公益 广告相结合，是社会主义思想现代化的必然要求。

公益广告具有明确的非赢利性、强烈的号召性、受众的广泛性、题材的朴素简懂。[2]公 益广告与绝大多数商业广告不同, 公益广告是不以营利为目的活动。公益广告取材于广大人 民群众, 从人民群众的利益出发, 为人们求利益, 谋发展, 得到人民群众的强烈反响, 具有 强烈的号召性。公益广告必须站在最广大人民的立场上, 力求广告能够影响到更多更广泛的 人。普通商业广告目的是推广自己的产品, 树立良好的企业形象, 为此, 不少企业广告设计 豪华奢侈。而公益广告从基层出发，力求每一个广告都能与人民产生共鸣，朴素易懂。

公益广告作为一种独特的传播形式, 具有四种基本的传播功能, 即: 促进功能、劝服功 能、增强功能和提示功能。通过公益广告来宣传社会主义核心价值观, 可以起到意想不到的 作用。公益广告具有促进信息的传播的功能, 向用户传递正能量的价值观, 能够加强受众现 有的知识, 使他们感知和了解广告信息。这种形式的公益广告最具有信息性。以公益广告的 方式传播社会主义核心价值观, 有利于使社会主义核心价值观传播得更远, 促进人们以社会 主义核心价值观为人生准则, 朝着社会主义核心价值观不断前进。

公益广告具有劝服的功能。当人们的行为出现错误, 或者人们的思想出现偏差, 公益广 告便可以发挥其劝服的功能。通过不断地对人们进行思想净化, 使人们认识到自身行为与思 想的偏差, 进行自我改正。

公益广告具有增强功能。当人们具有某一正确的思想观念，但是并不成熟时，公益广告 便可以发挥其增强的功能。公益广告以电视、手机等媒介, 不断地以各种形式出现在人们眼 前, 从而不断增强了人们的正确的思想, 朝着正确的方向行走。

公益广告具有提示功能。当人们逐渐淡忘了某一行为是否具有正确的意义时, 公益广告 便会起到提示作用, 以此来触发用户习惯性的行为。央视公益广告《请勿乱扔垃圾》, 通过 一件小事情来提示观众, 请勿乱扔垃圾, 从而使其深入人心，使环境更加优美。

\section{3. 应该如何更好地将公益广告与社会主义核心价值观结合起来}

广告传播就是把广告主所要传递的信息, 转换成偏重于感性、人性的符号, 通过适当的 媒介传递给广告对象。所以, 在进行公益广告创作的时候, 要以人民为本, 从人民群众本身 出发, 为广大人民群众量身定做高质量的公益广告。

而且公益广告必须要满足原创性、相关性、单一性、冲击性这四个要求。首先，原创性 是最基本的要求。公益广告要在对用户进行充分的分析的基础上制作, 切不可抄袭, 否则会 起到相反的作用。公益广告的创作还需要有很强的相关性, 要让用户立刻能够捕捉到广告所 要表达出来的意思。公益广告还需要满足单一性, 即所有元素都该为了成全一个核心想法而 存在, 没有第二个想法需要被顾及。在一个广告里面, 主要的核心的思想只有一个, 其他的 所有的想法都是为了主要思想而准备的, 都是它的衬托物品。做到了单一性, 广告的中心思 想才能够更容易被受众抓住。最后, 公益广告要有足够的冲击性和震撼力, 让受众看了之后 能够产生震撼或者共鸣, 引起受众的思考。 
现代广告尤其是以 21 世纪以来盛行的电视广告、互联网广告等新兴广告方式，具有直 观性强、传播速度快、受众面广等特点, 同时, 质量高的广告具有非常强的冲击力和感染 力，有利于加强受众对广告所要表达的含义的印象。在利用广告传播社会主义核心价值观 时, 不能停留在之前无目的没有正确方式的错误上面, 而要在充分了解处于社会主义新时代 广告传播和受众的基础上, 制作出符合社会主义核心价值观的广告。当然, 除了这些, 广告 本身的内容极其表现形式也不能忽视。公益广告所要表达出的内容, 必须是积极向上的, 不 能违背中国特色社会主义新时代的要求, 也必须是与时俱进的, 要学会批判继承旧的文化, 取其精华, 去其糟粕。在新时期, 广告表达的形式多重多样, 有视频广告、平面广告、广播 广告、h5 等, 但是无论是什么形式, 无论在什么地方进行传播, 公益广告想要加强受众的 对社会主义核心价值观印象, 想要产生良好的社会效果, 就要制作出能够和受众产生共鸣的 具有明确主题的符合传播规律的广告，这避免不了要求良好的广告制作技术。

当然，广告在一定程度上也有缺点。在广告传播过程中，受众是被动地接收广告信息， 这样受众容易产生抵抗情绪, 从而不利于信息传播, 还有可能产生相反的效果。所以, 在广 告的传播过程中, 广告主体要创新公益广告的传播方式, 要结合当代的各种新奇好玩的东 西, 针对社会社会上的各种问题，有针对性的地宣传。电视广告、平面广告、广播广告等大 多数广告都是让消费者被动接受信息, 而朋友圈等社交媒体则是一个消费者主动接受广告的 新地方。

根据拉斯韦尔“五 W 模式”，可将广告传播的构成要素归纳为五点：广告主体一一谁 (who)、广告讯息——说什么(what)、广告媒介——所通过的渠道(which channel)、广告受众 一向谁说(whom)、广告效果——取得什么效果(what effect)。在制作社会主义核心价值观 的广告时, 要始终坚持这 5 个 $\mathrm{W}$ 。广告主体, 是指广告信息的发送者, 它包括广告主和广 告公司。广告主体在创作公益广告的之前，需要对广告的受众即广大的人民群众进行调查， 以向人民群众传递正确的价值观为目的, 然后确定广告的内容, 再通过电视、网络、报纸等 媒体进行公益广告的投放, 投放结束后进行广告效果的计算。公益广告在传播的过程中坚持 这几个要素, 有利于使公益广告与社会主义核心价值观结合得更加紧密, 宣传效果更佳突 出。

\section{4. 结 语}

培育和践行社会主义核心价值观是推进中国特色社会主义伟大事业的重要一步，是实现 中华民族伟大复兴中国梦的战略任务。 ${ }^{[3]}$ 而公益广告这一信息传播方式，具有传播速度快、 直观等特点, 在今后的具体实践过程中若能够很好地将公益广告与社会主义核心价值观教育 紧密的融合起来, 肯定会达到更好的传播效果和教育效果, 助力实现中华民族的伟大复兴的 中国梦。

\section{References}

[1] W.Z. Lu, Popularization of socialist core values: learning and Enlightenment of Xi Jinping's thought of governing the country, Inheritance \& Innovation, vol.07, pp.80-81, 2016.

[2] W.Y Zhong and W.Z. Lu, Public service advertisement: the way of communication in the popularization of socialist core values, Reform \& Openning, vol.03, pp.62-64, 2017.

[3] X.X. Liu, Public service advertising and the dissemination of socialist core values, People's Tribune, vol.20, pp134-146, 2015.

[4] W.Y Zhong and W.Z. Lu, Public service advertisement: the way of communication in the popularization of socialist core values, Reform \& Openning, vol.03, pp.62-64, 2017. 